\title{
Prevalence of Male Infertility among the Infertile Couples Attended at BIRDEM General Hospital, Dhaka
}

\author{
Fahmin Rahman ${ }^{1}$, Mohiur Rahman ${ }^{2}$, Nusrat Mahmud ${ }^{3}$, G. U. Ahsan ${ }^{4}$, Mitheel-Ibna Islam ${ }^{5}$
}

\begin{abstract}
Background \& objective: Infertility is a problem of public health importance because of its high prevalence and serious social implications on affected couples and families. Although once believed that the problem is solely due to female factor, it is now generally accepted that male factor infertility is equally as important as the female factor. However, it is not known how far the problem is attributed to male factor. The present study is intended to find the prevalence of male infertility among the infertile couples and its determinants in the context of Bangladeshi population.
\end{abstract}

Patients \& Methods: The present study was a descriptive cross-sectional study conducted on male partners of infertile couples (over a period of three months) visiting the Infertility Clinic of Bangladesh Institute of Research and Development in Endocrine \& Metabolism (BIRDEM) General Hospital, Dhaka. Male infertility was defined as the inability of a man to make his partner conceive (because of quantitative and/or quantitative deficiency of his sperm) after 12 months of regular unprotected sexual intercourse. On the basis of semen analysis, male partners were divided into two groups - Infertile Group and Fertile Group and the suspected factors were compared between groups using crosstab analysis to determine the factors responsible for male infertility.

Result: The present study demonstrated that respondents were generally middle aged (between 30-50 years) with mean age being 35.5 years. Majority (88.5\%) was Muslim and belonged to middle class (74.3\%). Nearly half $(47 \%)$ was service-holder and one-third (35.8\%) was businessman. About $62 \%$ of the male partners were revealed to be infertile on semen analysis [combined prevalence of azoospermia (19\%), asthezoospermia $(29.2 \%)$ oligospermia $(12.8 \%)$, and teratzoospermia $(7.1 \%)$ ]. Of them nearly one-third (azoospermic ones) was solely responsible for infertility and the rest played contributing role to the overall infertility. The reproductive tract infection (STDs) was reported to be alarmingly high among infertile males (21.4\%) than that among their fertile peers $(p=0.002)$. Smoking, varicocele, overweight or obesity and diabetes also demonstrated their significant presence among infertile males compared to the fertile male group. History of occupational exposure to high temperature, pesticide, trauma to testes, abdominal and urogenital surgery were not associated with male partner fertility.

Conclusion: From the findings of the present study, it can be concluded that a substantial proportion of infertility can be attributed due to male partner infertility and its significant predictors are reproductive tract infections or sexually transmitted diseases. The second leading causes are varicocel, diabetes and obesity.

Key words: Prevalence, male infertility, determinants etc.

\section{Authors' information:}

${ }^{1}$ Dr. Fahmin Rahman, MBBS, MPH, Department of Publc Health, North South University (NSU), Bashundhara, Dhaka-1229, Bangladesh

${ }^{2}$ Dr. Mohiur Rahman, Registrar, Department of Urology, BIRDEM (Bangladesh Institute of Research and Rehabilitation in Diabetes, Endocrine and Metabolic Disorders) General Hospital, 122 Kazi Nazrul Islam Avenue, Dhaka-1000, Bangladesh

${ }^{3}$ Dr. Nusrat Mahmud, MBBS, MS, Consultant, Centre for Assisted Reproduction, Department of Obstetrics \& Gynaecology, BIRDEM (Bangladesh Institute of Research and Rehabilitation in Diabetes, Endocrine and Metabolic Disorders) General Hospital, 122 Kazi Nazrul Islam Avenue, Dhaka-1000, Bangladesh

${ }^{4}$ Professor Dr. G. U. Ahsan, Ph.D, MPHM, DTM\&H, MBBS, Dean, School of Health \& Life Sciences, North South University (NSU), Bashundhara, Dhaka-1229, Bangladesh

${ }^{5}$ Dr. Mitheel-Ibna Islam, MBBS, FCPS (Obstetrics \& Gynaecology), DGO, Medical Officer, 250 Bed Shaheed Sheikh Abu Naser Specialized Hospital, Khulna.

Correspondence: Dr. Fahmin Rahman, Phone: +8801733750170 E-mail:fahminrupa@gmail.com 


\section{INTRODUCTION:}

Infertility is a recognized reproductive health problem worldwide with a profound psychological impact on the of the affected couples. The World Health Organization (WHO) estimates that 60 to 80 million couples or $15 \%$ of the couples worldwide currently suffer from infertility. ${ }^{1}$ The problem of infertility in the world has grown to the extent that it is now a social and public health concern. $^{2}$ Following regular and frequent unprotected sexual intercourse, about $84 \%$ of couples in general population are expected to conceive within one year and about $92 \%$ should conceive within two years. ${ }^{3,4}$ When a couple fails to conceive even after one year of regular frequent coitus and there is no known reproductive pathology, the couple may be considered infertile. ${ }^{5}$ Although no epidemiological study has been conducted in the national level to assess the prevalence of infertility in Bangladesh, a global review of infertility from the World Fertility Survey estimated as $4 \%$ in Bangladesh. ${ }^{6}$ However, another estimate of overall primary and secondary infertility in South Asia suggests a much higher rate of $15 \%$ in Bangladesh. ${ }^{7}$

Contrary to the widespread belief that infertility is a female problem, infertility in the male partner contributes to approximately half of all cases. ${ }^{8}$ Even, in many studies infertility due to male factors is found to be the commonest single diagnostic category. ${ }^{9}$ But due to the male dominance of the social structure, females are often blamed for the reason. Males are found to be solely responsible for $20-30 \%$ of infertility cases and contribute to $50 \%$ of cases overall. ${ }^{10}$ According to the WHO, male infertility can be defined as one or more abnormalities within a semen analysis. ${ }^{11}$ It is now becoming more documented that there is a great variation in male infertility prevalence. Previous studies have documented a prevalence of about $40-50 \%$ in African society, whereas a study from Bangladesh found $29 \%$ of men attending an infertility clinic are infertile. ${ }^{12,13}$ A similar survey from Singapore found evidence of male infertility in $23 \%$, while a study of 1000 infertile couples in the USA recorded $30 \%$ infertile men. ${ }^{14,15}$ The prevalence of male infertility in Nigeria presently ranges from $20-25 \% .{ }^{16}$

Generally, the knowledge of male infertility lags behind knowledge of female infertility until recently. It is because that women are almost always the first member of an infertile couple to seek help. ${ }^{17}$ This is further compounded in our culture, where sexual potency is equated with normal male fertility potential and erroneous belief that reproduction is the sole responsibility of women. ${ }^{18}$ The other reasons include paucity of information and lack of cooperation of some affected men. ${ }^{19}$ It is, therefore, of utmost importance in investigating the prevalence of male infertility among infertile couples. However, on most occasions it has been found that, females are being treated for long time without assessing her male partner's fertility status. So it is very difficult to establish the relative contribution of the male partner in infertility. Although male infertility may result from various causes, certain causes and factors are preventable. Sexually transmitted diseases, cigarette smoking, alcohol consumption or taking recreational drugs like marijuana all are preventable causes male infertility. ${ }^{20}$ But no epidemiological study has yet been conducted on male infertility in our country. The present study was, therefore, intended to assess the prevalence of male infertility among infertile couples of Bangladesh.

\section{MATERIALS \& METHODS:}

This cross-sectional study was undertaken to assess the prevalence of male infertility among the infertile couples. The study was conducted over a period of 3 months in the Infertility Clinic of BIRDEM General Hospital, Dhaka. The infertile couples attending at the above mentioned clinic and who gave informed consent to participate in the study were included in the study. However, male partners with erectile and ejaculatory dysfunction or mentally unstable male partners were excluded from the study. Infertility was defined when female partner of a couple fails to conceive even after one year of regular coitus and there is no known reproductive pathology. Primary 
Infertility was applied to those who had never conceived, whereas secondary infertility was designated to those who ever conceived at some time in the past. The male infertility was defined as the inability of a man to make his partner conceive (because of quantitative and/or quantitative deficiency of his sperm) after 12 months of regular unprotected sexual intercourse. The condition may manifest as azoospermia (total absence of spermatozoa in semen) or oligozoospermia (sperm concentration $<15$ million per $\mathrm{ml}$ of semen. Sperm concentration 5-15 106/ml represents significant and $<5106 / \mathrm{ml}$ represent severe oligozoospermia) or asthenozoospermia (less than $40 \%$ of the sperm remain motile for more than 2 hours after ejaculation) or teratozoospermia (presence of $<40 \%$ morphologically normal forms of spermatozoa in the semen) or any combinations of the above mentioned conditions, such as oligo-terato-asthenozoospermia.

Behavioural factors (life-style factors and personal habit like cigarette smoking, alcohol intake, intake of tea or coffee, drug addiction and stress related to family and job) of the male partners were studied and were compared between infertile and fertile male partners to determine whether any of these factors carry the risk of having male partner infertility. Data were processed and analyzed using computer software SPSS (Statistical Package for Social Sciences). The test statistics used to analyse the data were descriptive statistics and Chi-square $\left(\chi^{2}\right)$ Test. The risk of developing male infertility due to exposure to a particular factor was estimated using Odds Ratio with its $95 \%$ confidence interval. The level of significance was set at 0.05 and $p<0.05$ was considered significant.

\section{RESULTS:}

Demographic characteristics of the respondents are presented in Table I. About $63 \%$ of the respondents presented to our infertility clinic at their early middle age (30-40 years), 23\% at middle age, $12.4 \%$ early years of married life (< 30 years). The mean age at presentation is 35.5 (range: $23-52$ ) years. Majority (88.5\%) was Muslim. Over one-quarter $(27.8 \%)$ of the patients were masters level educated followed by $22.6 \%$ HSC, $21.7 \%$ SSC and $11.9 \%$ primary, $11.1 \%$ graduate level educated. In terms of occupation, over one-third (34.5\%) was private service-holder and another one-third (35.8\%) was businessman and $12.4 \%$ govt. service-holder. About $75 \%$ were middle class (based on income), $14.2 \%$ lower and $11.1 \%$ upper class. Majority (92.5\%) did not have any history of adverse environmental exposure. Only $4.4 \%$ reported occupational exposure to high temperature, $1.3 \%$ to pesticide, $0.9 \%$ to radiation and another $0.9 \%$ to chemical etc. The mean duration of exposure was 9.1 years (Table II). About half $(49.1 \%)$ of the respondents were smoker. The mean duration of smoking was 13 years and the mean number of sticks smoked each day was $8 \pm 2$. About $5 \%$ were alcoholics. Over half $(50.8 \%)$ of the respondents was overweight or obese. Over $45 \%$ maintained good relationship with their spouse and other family members and over-one-third $(36.7 \%)$ did not have a good relationship. Over $10 \%$ suffered from chicken pox, $2.3 \%$ suffered from mumps. History of suffering from TB was rare. About $10 \%$ had diabetes with mean duration of suffering from the disease being 4.8 years. Over $10 \%$ of the respondents were hypertensive with mean duration of hypertension being 3.9 years. More than $15 \%$ had sexually transmitted diseases (Table III). Eleven percent of the respondents gave the history of trauma to the testes, $14.2 \%$ had history of suffering from varicocele. Majority did not have any history of operation. (Table IV). The findings of semen analysis with mean and SD/SEM are illustrated in Table V. Based on the findings of semen analysis $29.2 \%$ had asthenozospermia alone and 19\% azoospermia alone. The rest had different combinations with asthenozoospermia.

Table VI shows the association of certain putative factors with male partner infertility. The infertile males were frequently overweight or obese and smoker compared to their fertile counterparts ( $p=0.043$ and $p=0.034$ respectively). Sexually transmitted diseases (STDs) were staggeringly higher among infertile males than that among their fertile peers $(p=0.002)$. Varicocele also 
demonstrated its significant presence in the former group than that in the latter group ( $p=$ 0.014 ). Diabetes bears a marginally significant association with male infertility $(p=0.060)$, and smoking habit was considerably higher among the infertile males $(p=0.034)$. All other factors shown in the table were not found to be associated with male infertility. The risks of having infertility in males with STD, varicocele smoking/tobacco use and overweight or obesity are estimated to be $4.41(95 \% \mathrm{CI}=1.64-11.88)$, $3.08(95 \% \quad C I=1.21-7.84), \quad 1.80(95 \% \quad C I=1$. 04-3.11) \& 1.75(95\% CI=1.02- 3.01) times higher respectively than those who do not have these factors.

\begin{tabular}{|c|c|c|}
\hline Demographic characteristics & Frequency & Percentage \\
\hline \multicolumn{3}{|l|}{ Age (yrs) } \\
\hline$<30$ & 28 & 12.4 \\
\hline $30-40$ & 142 & 62.8 \\
\hline $40-50$ & 52 & 23.0 \\
\hline$\geq 50$ & 4 & 1.8 \\
\hline \multicolumn{3}{|l|}{ Religion } \\
\hline Muslim & 200 & 88.5 \\
\hline Hinduism & 25 & 11.1 \\
\hline Christian & 1 & 0.4 \\
\hline \multicolumn{3}{|l|}{ Education } \\
\hline Illiterate & 2 & 0.9 \\
\hline Primary & 27 & 11.9 \\
\hline SSC & 49 & 21.7 \\
\hline $\mathrm{HSC}$ & 51 & 22.6 \\
\hline Graduate & 25 & 11.1 \\
\hline Masters & 63 & 27.9 \\
\hline Non-formal education & 9 & 4.0 \\
\hline \multicolumn{3}{|l|}{ Occupation } \\
\hline Govt. service & 28 & 12.4 \\
\hline Private & 78 & 34.5 \\
\hline Business & 81 & 35.8 \\
\hline Teacher & 11 & 4.9 \\
\hline Others & 28 & 12.4 \\
\hline \multicolumn{3}{|l|}{ Social Class (Monthly taka) } \\
\hline Lower $(<15000)$ & 32 & 14.2 \\
\hline Middle (15000-40000) & 168 & 74.3 \\
\hline Upper middle (40000-60000) & 25 & 11.1 \\
\hline Rich $(>60000)$ & 1 & 04 \\
\hline
\end{tabular}

\# Mean age $=(35.5 \pm 5.7)$ years; range $=(23-52)$ years

TABLE II : Distribution of respondents by occupational exposure $(n=226)$

\begin{tabular}{|cccc}
\hline $\begin{array}{l}\text { Occupational } \\
\text { exposure }\end{array}$ & Frequency & Percentage & Mean \pm SD \\
\hline High temperature & 10 & 4.4 & \\
Radiation & 2 & 0.9 & \\
Chemical & 2 & 0.9 & \\
Pesticide & 3 & 1.3 & \\
$\quad$ None & 209 & 92.5 & \\
Duration of exposure (years) & & & $9.1 \pm 3.1$
\end{tabular}

TABLE III : Behavioural and anthropometric characteristics of the respondents

Behavioural and

anthropometric

Frequency Percentage Mean $\pm S D$ characteristics

Smoking related profile

Smoker

Duration of smoking (yrs)

Stick per day $(n=107)$

107

107

47.3

$-$

$12.9 \pm 11.2$

$8.3 \pm 2.5$

Alcoholic

Overweight \& obese

(BMI $25-29.9 \mathrm{~kg} / \mathrm{m}^{2}$ )

Relation with family members

Good

Better

Not well

Disease suffered

Mumps

Chicken pox

TB

Never suffered

Diabetics

Duration of DM (years)

Hypertension

Duration of HTN (years)

Medication taking ( $\mathrm{n}=93$ )

Antihypertensive

$\mathrm{H}_{2}$ Blocker

Antipsychotic drugs

STD

11

115

4.9

50.8

$102 \quad 45.1$

$41 \quad 18.1$

$83 \quad 36.7$

$5 \quad 2.3$

$24 \quad 10.6$

$2 \quad 0.9$

$195 \quad 86.3$

$21 \quad 9.3$

$23 \quad 10.2$

$4.8 \pm 3.9$

$3.9 \pm 2.6$

TABLE IV: Distribution by other risk factors (trauma to testes, varicocele or surgery)

\begin{tabular}{lcc}
\hline Surgical history & Frequency & Percentage \\
\hline Trauma to testis & 25 & 11.1 \\
Suffering from varicocele & 32 & 14.2 \\
History of operation & & \\
$\quad$ No surgery & 226 & 96.5 \\
Abdominal surgery & 2 & 0.9 \\
Urogenital surgery & 2 & 0.9 \\
Herniorraphy & 1 & 0.4 \\
Hydrocele surgery & 3 & 1.3
\end{tabular}




\begin{tabular}{|c|c|c|c|c|c|}
\hline \multicolumn{2}{|l|}{ Semen profile } & \multicolumn{2}{|c|}{ Frequency (\%) } & \multicolumn{2}{|c|}{ Mean \pm SD/SEM } \\
\hline \multicolumn{6}{|c|}{ Physical characteristcs } \\
\hline \multicolumn{3}{|l|}{ Volume (ml) } & --- & \multicolumn{2}{|c|}{$2.48 \pm 1.17$} \\
\hline \multicolumn{2}{|c|}{ Concentration $(\times 106 \mathrm{ml})$} & & -- & \multicolumn{2}{|c|}{$65.88 \pm 4.50$} \\
\hline \multicolumn{2}{|l|}{ Motility (\%) } & & --- & \multicolumn{2}{|c|}{$30.41 \pm 21.63$} \\
\hline \multicolumn{2}{|c|}{ Abnormal morphology (\%) } & & --- & \multicolumn{2}{|c|}{$39.91 \pm 22.13$} \\
\hline \multicolumn{6}{|c|}{ Outcome of semen analysis } \\
\hline & $86(38.1)$ & \multicolumn{2}{|c|}{---} \\
\hline \multicolumn{3}{|l|}{ Azoospermia } & $43(19.0)$ & \multicolumn{2}{|c|}{--} \\
\hline \multicolumn{3}{|c|}{ Asthenozoosparmia only } & $66(29.2)$ & \multicolumn{2}{|c|}{--- } \\
\hline \multicolumn{3}{|c|}{ Asthenozoosparmia+Teratozoosparmia } & $2(0.01)$ & \multicolumn{2}{|r|}{---} \\
\hline \multirow{2}{*}{\multicolumn{3}{|c|}{$\begin{array}{l}\text { Oligospermia+Asthenozoosparmia } \\
\text { Oligospermia+Asthenozoosparmia+ }\end{array}$}} & $17(7.4)$ & \multicolumn{2}{|c|}{--} \\
\hline & & & $12(5.3)$ & \multicolumn{2}{|r|}{---} \\
\hline \multicolumn{6}{|c|}{ TABLE VI: Risk of infertility in male partners of infertile couples } \\
\hline \multirow[b]{2}{*}{ Variables* } & \multicolumn{2}{|c|}{ Fertility status } & \multirow{2}{*}{\multicolumn{2}{|c|}{$\begin{array}{l}\text { Odds Ratio } \\
\text { (95\% Cl of OR) }\end{array}$}} & \multirow[b]{2}{*}{ p-value } \\
\hline & $\begin{array}{l}\text { Infertile } \\
(n=140)\end{array}$ & $\begin{array}{l}\text { Fertile } \\
(n=86)\end{array}$ & & & \\
\hline $\begin{array}{l}\text { Occupational } \\
\text { exposure }\end{array}$ & $11(7.9)$ & $6(7.0)$ & $1.1(0.4 C$ & $0-3.19)$ & 0.808 \\
\hline $\begin{array}{l}\text { BMI }\left(\geq 25 \mathrm{~kg} / \mathrm{m}^{2}\right) \\
\text { Smoking/ }\end{array}$ & 78(55.7) & $36(41.9)$ & 9) $\quad 1.75(1.0$ & $2-3.01)$ & 0.043 \\
\hline Tobacco use & $74(52.9)$ & $33(38.4)$ & 4) 1.80( & $4-3.11)$ & 0.034 \\
\hline Alcohol & $7(5.0)$ & $4(4.7)$ & $1.08(0.3$ & $31-3.80)$ & 0.906 \\
\hline DM & $17(12.7)$ & $4(4.9)$ & $2.8(0.92$ & 2-8.73) & 0.060 \\
\hline HTN & $16(12.1)$ & $7(8.5)$ & $1.5(0.58$ & 8-3.76) & 0.410 \\
\hline STD & $30(21.4)$ & $5(5.8)$ & $4.41(1.64$ & $4-11.88)$ & 0.002 \\
\hline H2-blocker & $42(64.6)$ & $19(67.9)$ & 9) $\quad 0.87(0.3$ & $34-2.22)$ & 0.763 \\
\hline Trauma to testes & $16(11.8)$ & $9(10.5)$ & $1.14(0.4$ & $8-2.71)$ & 0.765 \\
\hline Varicocele & $26(19.0)$ & $6(7.1)$ & $3.08(1.2$ & (1-7.84) & 0.014 \\
\hline
\end{tabular}

Figures in the parentheses indicate corresponding \%; ${ }^{*}$ Chi-squared Test $\left(\chi^{2}\right)$ was done to analyse the data.

\section{DISCUSSION:}

According to WHO guideline, if an adult male has a sperm count below 20 million per ejaculate, sperm motility below $50 \%$ and abnormal morphology $>40 \%$, the individual is considered as infertile. According to this guideline, a $62 \%$ prevalence of male partner infertility [combined prevalence of azoospermia (19\%), asthezoospermia (29.2\%) oligospermia (12.8\%), and teratzoospermia (7.1\%)] was evident in the present study. Quite consistent with this finding Bashed et $\mathrm{al}^{21}$ in a study conducted in the Infertility Treatment \& Research Centre, Dhaka demonstrated a prevalence of male infertility of $60 \%$ among infertile couples. In African countries $40 \%$ of all couples experiencing infertility, have a male factor responsible for the condition. The male factor is associated with a greater percentage of cases of primary rather than secondary infertility. ${ }^{22}$ This was reported to be as high as 59\% in France, ${ }^{23} 35 \%$ in Nigeria, 26-32 \% in the UK and about $36 \%$ in South Africa, Indonesia and Finland. ${ }^{24,25}$ The high level of infertility in Africa is due largely to reproductive tract infections which may be associated with abnormal semen parameters and low sperm count. ${ }^{26-28}$ In a Nigerian study, $42.5 \%(n=171)$ of the subjects had a sperm count of less than 20 million per $\mathrm{ml} ; 13.9 \%(n=56)$ of the subjects had azoospermia, while $53.2 \%(n=214)$ had sperm motility of less than $50 \% .{ }^{29}$ Nigerian gynecologists frequently report that infertility cases constitute between 60 and $70 \%$ of their consultations in tertiary health institutions. ${ }^{30}$

In the present study as well history of reproductive tract infection (STDs) was reported to be alarmingly high among infertile males $(21.4 \%)$ than that among their fertile peers. The male factor contribution to infertility in the Nigerian populations seems to be very high. Varicocel, obesity and diabetes also demonstrated their significant presence among infertile males compared to the fertile male group. Smoking behavior was significantly higher in the infertile group than that in the fertile group. History of occupational exposure to high temperature, pesticide, trauma to testes, abdominal and urogenital surgeries were not found to influence male partner fertility. Anwary et $\mathrm{al}^{31}$ in an attempt to study the male infertility at Bangabandhu Sheikh Mujib Medical University (BSMMU) during 2007-08, found medical disorders in 6\%, history of mumps in $6 \%$, history of orchitis in $4 \%$, diabetes in $2 \%$, history of smoking in $28 \%$.

Investigating into the causes of male infertility worldwide, it is revealed that the failure of spermatogenesis and obstruction of the ductal system particularly the vas deferens were reported as the causes of the azoospermia and that the obstruction of the vas deferens was not a 
major cause of azoospermia. ${ }^{32}$ It was reported that infection of the seminal fluid was the major cause of azoospermia in infertile males as infection is known to damage the vas deferens and seminiferous tubules thereby affecting the circulating level testosterone. ${ }^{33}$ It is now thought that post bacterial infections and idiopathic testicular pathology are common causes of azoospermia in Nigerian environment ${ }^{32}$ and oligospermic semen is prone to be associated with bacterial infection. ${ }^{34}$ These data seem to suggest that abnormal semen quality remains a significant contribution to overall infertility and may be associated with genital infections. In the present study, there was a higher prevalence of reproductive infections in male partner infertility and is almost comparable to those found in Nigerians suggesting that inflammatory conditions contribute more to male infertility in developing countries $^{35}$ like ours. However, a WHO study suggests that $58 \%$ of Asian men have no demonstrable cause and another $25 \%$ revealed an abnormal semen without etiological factors. The major identifiable cause of male infertility was Varicocele, affecting roughly $10 \%$ of all infertile men and infectious factors affecting another 5\%.36

Presently male partner infertility issue is often faced by many couples. However, ours is a male-dominating society, it is so seldom talked about openly. The contribution of male partner towards couple's infertility problem was not considered seriously until the 1950s. Most textbook until then emphasized primarily the role of the female partner in this problem. Popularization of detailed analysis of semen and testicular abnormalities towards disorder of sperm production, confirm the contribution of the male partner to the couple's infertility. ${ }^{37}$

The staggeringly high prevalence of male infertility data may seem unbelievable to many of our gynaecologists, venerologists or epidemiologists. But when one considers that the study was done in BIRDEM and that a recent study done by Bashed et $\mathrm{al}^{38}$ on 9000 couples demonstrated a similar report $(60 \%$ prevalence of male partner infertility among infertile couples), it may not be surprising. To further judge the plausibility of the findings of the present study, let us look at the findings of similar studies conducted around the world.

Majority of young men in the 1940s had sperm counts far above 40 million per $\mathrm{ml}$ with averages higher than 100 million per ml. In today's Western industrialized countries, not only are sperm counts decreasing, the proportion of sperm with abnormal morphology and reduced motility is also increasing. For example, the proportion of sperm with abnormal morphology increased (from 26\% to $45 \%$ ) and sperm motility decreased ${ }^{39}$ in a Danish study while in Oslo, Norway, the proportion of abnormal sperm rose from 40 to $59 \%$ between 1966 and $1986 . .^{40}$ Some studies have suggested that the semen quality of sperm of young men in Northern Europe is declining. ${ }^{41}$ Other reports have confirmed the presence of extraordinarily poor semen quality among otherwise healthy young men in the general population. ${ }^{42}$

Carlsen and colleagues ${ }^{43}$ first raised the possibility of a substantial fall in male fertility levels in 1992. They reported that sperm concentration in healthy men appeared to have dropped from 113 million/ml in 1940 to 66 million/ml in 1990. Subsequent studies have confirmed and strengthened Carlsen's findings. A survey of 1,350 sperm donors in Paris found a decline in sperm counts by around $2 \%$ each year over the past 23 years with total decline of $32 \%$ and with younger men having the poorest-quality semen. ${ }^{44}$ Similar studies have also found that sperm counts in the United States dropped by about $25 \%$ during the $1980 s^{45}$ and in Denmark dropped by about $25 \%$ between 1952 and 1972.46

Data available over the past 20 years reveal that in approximately $30-50 \%$ of the cases of infertility, the cause is found in the man alone, and in another $20 \%$, the causes are found in both ${ }^{47}$ and in $50-70 \%$, the causes are found in the female alone. ${ }^{48}$ The concern about this adverse trend in male reproductive health is that semen samples where the concentration of sperms is below 40 million per $\mathrm{ml}$ may be associated with longer time to conception or even subfertility, and low sperm count where the concentration of 
sperms is below 15 million per $\mathrm{ml}$ may be associated with higher risk of infertility. The difficulty inherent in defining infertility in this manner is obvious: some couples without reproductive dysfunction who wish to conceive fail to do so probably due to inadequate coital exposure or timing, while others have reproductive-system dysfunction that prevents conception. However, the downward trend in sperm quality and concentration is definitely a cause of concern for male fertility in future.

\section{CONCLUSION:}

From the findings of the present study, it can be concluded that a substatial proportion of infertility can be attributed to male partner infertility and its significant predictors are reproductive tract infections or sexually transmitted diseases. The second leading causes are smoking, varicocel, diabetes \& obesity. History of occupational exposure to high temperature, pesticide, trauma to testes, abdominal and urogenital surgeries are not found to influence male partner fertility in the present study. However, further study is recommended to study the association of these factors with male infertility to validate the findings of the present study. As all these factors are closely associated with human behavior and life-style, the future incidence of male infertility is expected to rise, unless the policy-makers take immediate step to contain these factors by behavior change, communication and occupational safety measure.

\section{References:}

1. Sciarra J. Infertility: an international health problem. Int J Gynaecol Obstet 1994;46:155-63.

2. Anate $M \&$ Akeredolu $O$. Attitude of male partners to infertility management in Ilorin. NM Pract 1994;27: 46-49.

3. te Velde ER, Eijkemans R \& Habbema HDF. Variation in couple fecundity and time to pregnancy, an essential concept in human reproduction. Lancet 2000;355:1928-9.

4. Bongaarts J. Amethod for the estimation of fecund ability. Demography 1975;12:645-60.

5. Hull MG, Glazener CM, Kelly NJ, Conway DI, Foster P A, Hinton RA, et al. Population study of causes, treatment, and outcome of infertility. BMJ 1985;291:1693-97.
6. Farely TMM \& Beisy EM. The prevalence and etiology of infertility. Paper presented at the African population conference, sponsored by the IUSSP and the central statistical office, Senegal, Dhaka, November, 1988.

7. Kumar D. Prevalence of female infertility and its socioeconomic factors in tribal communities of central India. Rural Remote Health 2007; 7:456.

8. Ayaz KFM, Ahasan HAMN, Raihan MR, Miah MT, Haque MA \& Siddique AA. Male Infertility - A Review. Bangladesh Society of Medicine, Dec 06, 2012, Cited [Internet]06/05/2017 10:01:59 AM]; available at: https://www.mysciencework.com/publication/show/male-infertility-a-review

9. Haxton MJ \& Black WP. The aetiology of infertility in 1162 investigated couples. Clin Exp Obstet Gynecol 1987; 14(2):75-9.

10. Agarwal A, Mulgaund A, Hamada A \& Chyatte MR. A unique view of male infertility around the globe. Reproductive Biology and Endocrinology 2015;13:1-9.

11. World Health Organization. WHO Laboratory manual for the examination of spermatosis and sperm. Cervical Mucus infection, $3^{\text {rd }}$ ed. London: Cambridge University Press, 1999.

12. Ladipo AO. The Epidemiology of Infertility. Dokita $1987 ; 16: 1-5$.

13. Chowdhury TA, Khanom ST, Akhter M \& Habib F. Profile of 350 Couples Attending the Infertility Clinic at P. G. Hosp. In: Bangladesh Fertility Research Pro. Dacca. Fifth Contributors conference, 1981;85-92.

14. Ratnam SS, Shew PCT \& Tskole M. "Experience of a Comprehensive Infertility Clinic in the dept. of OAG, University of Singapore. Medical Journal 1976;17(3): 157-9.

15. Tayonor MC. Infertility. New York: Grune and Straton. $1978 ; 216$.

16. Ajarbo LN, Ezimokha M \& Kadiri A. Male Contribution to Sub- fertility in Benin- city, Nigeria. Trop J Obstet \& Gynaecol 1981;2:23-56.

17. Matthew T, Mati, JKG \& Formulu JN. A study of Infertility in Kenya: Results of Investigation of the Infertile Couple in Nairobi. East African Journal of Medicine $1981 ; 58: 288-97$.

18. Oladipo OA \& Seminla. Analysis of Fertility and Infertile Nigerian men. $J$ of Nat Med Association $1980 ; 72(8): 785-89$.

19. Nwabuisi C \& Onile BA. Male infertility among sexually transmitted diseases clinic attendees in Ilorin, Nigeria. NMJ 2001;2:68-71.

20. Hanoom H. Selected reproductive health elements and interventions. editorial BIRPERHT 1997;1:77-9. 
21. Bashed MA, Gazi MA, Kadir MA and Al-Amin AQ. Male infertility in Bangladesh:What Bette-Phermacological Help or Awareness Programme? Int J Pharm 2012; 8(8):687694.

22. Araoye MO. Epidemiology of infertility: social problems of the infertile couples. WAJM 2003;22:190-96.

23. Thonneau P, Marchand S, Tallec A, Ferial ML, Ducot B, Lansac $J$ et al. Incidence and main causes of infertility in a resident population $(1,850,000)$ of three French regions (1988-1989). Hum Reprod 1991;6:811-16.

24. Mehta RH, Makwana S, Ranga GM, Srinivasan RJ \& Virk SS. Prevalences of oligozoospermia and azoospermia in male partners of infertile couples from different parts of India. Asian J Androl 2006;8:89-93.

25. Fisch H \& Goluboff ET. Geographic variations in sperm counts: a potential cause of bias in studies of semen quality. Fertil Steril 1996;65:1009-14.

26. Ugwuja E, Ugwu NC \& Ejikeme BN. Prevalence of Low Sperm Count and Abnormal Semen Parameters in Male Partners of Women Consulting at Infertility Clinic in Abakaliki, Nigeria. Afr Reprod Health 2008;12:67-73.

27. Ikechebelu JI, Adinma JI, Orie EF \& Ikegwonu SO. High prevalence of male infertility in South-eastern Nigeria. J Obstet Gynaecol 2003;23:657-59.

28. Okonofua FE. Infertility in Sub-Saharan Africa. In: Okonofua F, and L Odunsi, eds. Contemporary Obstetrics \& Gynaecology for Developing Countries. Women's Health and Action Research Centre 2003:128-56.

29. Loto OM. Profiles of the semen analyses of male partners of infertile couples in a Nigerian population. Int Congress Series 2004;271:57-59.

30. Umeora OUJ, Ejikeme BN, Sunday-Adeoye I \& Umeora MC. Sociocultural impediments to male factor infertility evaluation in rural South-east Nigeria. J Obstet Gynaecol $2008 ; 28: 323-26$.

31. Anwary SA, Alfazzaman \& Islam MR. Male sub-fertile patients in a tertiary hospital. Mymensingh Med J 2011;20:33-9.

32. Emokpae MA \& Emokpae LA. Calcium concentration in semen of azoospermic Nigerians. J Med Lab Sci $1997 ; 6: 42-43$

33. Megafu U. Seminal fluid infection and oligospermia. Trop J Obstet Gynecol 1991;9;10-12.

34. Ugwuja E, Ugwu NC \& Ejikeme BN. Prevalence of Low Sperm Count and Abnormal Semen Parameters in Male Partners of Women Consulting at Infertility Clinic in Abakaliki, Nigeria. Afr Reprod Health 2008;12:67-73.
35. Ogunbanjo BO, Osoba AO \& Ochei J. Infective factors of male infertility among Nigerians. Afr J Med MedSci 1989;18:35-38.

36. Ahmed AU. Socio economic determinants of divorce in Bangladesh. Rural demography 1987;14(1-2):61-77.

37. Chowdhury TA \& Khanam ST. A study on male infertility. Bangladesh M J 1983; 12:96-100.

38. Bashed MA, Gazi MA, Kabir MA \& Al- Amin AQ. Male infertility in Bangladesh: What Better- Phermacological Help or Awareness Programme? Int $J$ Pharm 2012;8(8):687-94.

39. Bostoffe E, Serup J \& Reba H. Has the fertility of Danish men declined through the years in terms of semen quality? A comparison of semen qualifies between 1952 and 1972. Int J Fert 1983;28:91-95.

40. Bendvold E. Semen quality in Norwegian men over a 20-year period. Intl J Fert 1989;34:401-04.

41. Van Waeleghem K, De Clercq N \& Vermeulen L. Deterioration of sperm quality in young Belgian men during recent decades. Hum Reprod 1994;9:73.

42. Jørgensen N, Vierula M, Jacobsen R, Pukkala $E$, Perheentupa A, Virtanen HE et al. Recent adverse trends in semen quality and testis cancer incidence among Finnish men. Int $J$ Androl 2011;34(4pt2): e37-e48. doi: 10.1111/j.1365-2605.2010.01133.x

43. Jørgensen N, Asklund C, Carlsen E. Coordinated European investigations of semen quality: result from studies of Scandinavian young men is a matter of concern. Int J Androl 2006;29:54-61.

44. Carlsen E, Giwercman A, Keiding N \& Skakkebaek NE. Evidence for decreasing quality of semen during past 50 years. Brit Med J 1992;305:609-13.

45. Cates W, Farely TMM \& Rowe PJ. Patterns of infertility in developed and developing worlds'. In Rowe Patrick J. AND Ekaterina Michailova Vikhlyaeva, eds. Diagnosis and treatment of infertility. Bern:Hans Huber publishers; 1985.

46. Itoh N, Kayama F, Tatsuki TJ \& Tsukamoto T. Have sperm counts deteriorated over the past 20 years in healthy young Japanese men? Results from the Sapporo area. J Androl 2001;22:40-44.

47. Inhorn MC \& Buss KA. Ethnography, epidemiology and infertility in Egypt. Social science in medicine 1994;39 (5):671-86.

48. Demetrius JP. Male Infertility: Diagnosis and Treatment J Nurse Pract 2006;2:298-99. 